\title{
Genome-wide identification of the Fermentome; genes required for successful and timely completion of wine-like fermentation by Saccharomyces cerevisiae
}

Michelle E Walker ${ }^{1,2}$, Trung D Nguyen ${ }^{1,2}$, Tommaso Liccioli, ${ }^{1,2}$, Frank Schmid ${ }^{1,2}$, Nicholas Kalatzis ${ }^{1,2}$, Joanna F Sundstrom ${ }^{1,2}$, Jennifer M Gardner ${ }^{1,2}$ and Vladimir Jiranek ${ }^{1,2^{*}}$

\begin{abstract}
Background: Wine fermentation is a harsh ecological niche to which wine yeast are well adapted. The initial high osmotic pressure and acidity of grape juice is followed by nutrient depletion and increasing concentrations of ethanol as the fermentation progresses. Yeast's adaptation to these and many other environmental stresses, enables successful completion of high-sugar fermentations. Earlier transcriptomic and growth studies have tentatively identified genes important for high-sugar fermentation. Whilst useful, such studies did not consider extended growth ( $>5$ days) in a temporally dynamic multi-stressor environment such as that found in many industrial fermentation processes. Here, we identify genes whose deletion has minimal or no effect on growth, but results in failure to achieve timely completion of the fermentation of a chemically defined grape juice with $200 \mathrm{~g} \mathrm{~L}^{-1}$ total sugar.

Results: Micro- and laboratory-scale experimental fermentations were conducted to identify 72 clones from $~ 5,100$ homozygous diploid single-gene yeast deletants, which exhibited protracted fermentation in a high-sugar medium. Another 21 clones (related by gene function, but initially eliminated from the screen because of possible growth defects) were also included. Clustering and numerical enrichment of genes annotated to specific Gene Ontology (GO) terms highlighted the vacuole's role in ion homeostasis and $\mathrm{pH}$ regulation, through vacuole acidification.

Conclusion: We have identified 93 genes whose deletion resulted in the duration of fermentation being at least 20\% longer than the wild type. An extreme phenotype, 'stuck' fermentation, was also observed when DOA4, NPT1, PLC1, PTK2, SIN3, SSQ1, TPS1, TPS2 or ZAP1 were deleted. These 93 Fermentation Essential Genes (FEG) are required to complete an extended high-sugar (wine-like) fermentation. Their importance is highlighted in our Fermentation Relevant Yeast Genes (FRYG) database, generated from literature and the fermentation-relevant phenotypic characteristics of null mutants described in the Saccharomyces Genome Database. The 93-gene set is collectively referred to as the 'Fermentome'. The fact that 10 genes highlighted in this study have not previously been linked to fermentation-related stresses, supports our experimental rationale. These findings, together with investigations of the genetic diversity of industrial strains, are crucial for understanding the mechanisms behind yeast's response and adaptation to stresses imposed during high-sugar fermentations.
\end{abstract}

\footnotetext{
* Correspondence: vladimir.jiranek@adelaide.edu.au

${ }^{1}$ School of Agriculture, Food and Wine, University of Adelaide, Urrbrae, SA

5064, Australia

${ }^{2}$ Wine Innovation Cluster, Adelaide, South Australia
} 


\section{Background}

Saccharomyces cerevisiae strains are widely used for production of alcoholic beverages such as wine, beer, sake, as well as bioethanol. The selection of yeast strains for efficient fermentation performance in these industrial processes has typically focused on attributes such as predictable fermentation at the relevant process temperatures, desired fermentation vigour and extent of sugar attenuation with efficient conversion to ethanol. Attributes deemed important for wine fermentation include retention and enhancement of varietal (grape derived) fruit characters and production of desirable flavour and aroma compounds [1]. The numerous subtle differences in fermentation traits between the various industrial yeast strains are reflected in the overall genetic diversity found in this species [2]. Nevertheless, industrial yeast share the ability to grow and ferment in high sugar media, sensing, responding and adapting to the extreme and changing conditions. Such conditions are imposed by anaerobic conditions, high concentrations of sugar and organic acids (resulting in high osmotic pressure), toxins and inhibitors, at times low $\mathrm{pH}$ and assimilable nitrogen levels, extended fermentation times and increasing concentration of ethanol or other inhibitors. Our understanding of the cellular mechanisms behind yeast's adaptation to the temporal exposure to multiple environmental stresses in such fermentations is limited despite extensive studies in the past decade.

Extensive 'phenomic' studies have been undertaken with laboratory yeast collections, comprised of individual known single gene deletion mutants (deletants), whereby the phenotype of such deletants is analysed to determine the genes associated with tolerance to a specific condition. Several studies have looked at tolerance or growth sensitivity to singular conditions related to high sugar fermentation, including high osmolarity (specifically sucrose [3] and glucose [4]), anaerobic growth [5], oxidative stress [6], tolerance to high pressure and low temperatures [7], ethanol [8-10] and acetic acid [11]. These studies typically did not require the completion of fermentation and were conducted under aerobic conditions usually for 1-3 days only.

This study is unique in that it sought to identify genes required by yeast to not only grow in but to complete fermentation of a high sugar medium, that is a chemically defined grape juice, wherein multiple stresses would be experienced simultaneously or sequentially. The non-availability of a deletion library in a prototrophic wine yeast background necessitated the use of the laboratory yeast library, derived from S288c [12]. Although these lab yeast strains are reported to cope poorly with high osmotic pressure as found in grape juice [13], we and others have shown that the S288c derived diploid BY4743 and haploids BY4741 (data not shown) and BY4742 [13], are able to complete fermentation in high sugar media [14,15], provided their auxotrophic requirements are met.

Previous studies have identified genes essential for growth under particular conditions relevant to fermentation, but not the entire fermentation process itself. Sufficient biomass is critical for fermentation performance; if there is too little, fermentation becomes severely protracted or may even fail to complete. Adequate biomass does not however guarantee fermentation completion, especially in high sugar media. Furthermore, whilst transcriptomic experiments highlighted genes whose expression was significantly altered during fermentation, these genes are not necessarily required for fermentation reliability.

This report relates to the effect of gene deletions on yeast's ability to complete extended high sugar fermentation. Those deletants whose maximum biomass was at least $70 \%$ of the parent but which exhibited protracted (or stuck) fermentation were taken to highlight genes fundamental for successful fermentation in high sugar conditions, such as in wine production. The clustering of these into specific groupings i.e. Gene Ontology (GO) terms provides insight into the many cellular mechanisms behind yeast's adaptation to fermentation stresses.

\section{Results and discussion}

\section{A micro-fermentation screen to identify genes required} for successful fermentation in a high sugar medium

In this study (outlined in Figure 1), a high throughput fermentation screen was developed to identify those genes required for high sugar (i.e. akin to wine) fermentation, whereby deletion of the corresponding genes would result in protracted or arrested fermentation. Whereas previous screens have focused on growth assays using standard laboratory media such as YPD supplemented with a stress agent (e.g. ethanol, sugar, oxidizing compounds), our approach was to test the ability of yeast to complete extended fermentation, albeit on a micro-scale. The ability to undergo a wine fermentation requires the yeast to respond and adapt to a dynamic and temporal exposure to multiple stresses in the 'juice' environment. Specifically, upon inoculation the cell population must be able to grow to a high density whilst exposed to high osmotic conditions (imposed by the sugars and organic acids in the juice) and the rapid depletion of oxygen and nitrogenous nutrients, sterols and vitamins [16]. With the bulk of fermentation being conducted by cells in stationary phase, long-term adaptation is paramount to the cell's tolerance to increasing levels of ethanol, as a consequence of sugar uptake and catabolism.

Chemically defined grape juice medium (CDGJM_200) containing $200 \mathrm{~g} \mathrm{~L}^{-1}$ sugar (as equimolar amounts of glucose and fructose) was chosen for the high sugar medium. Whilst fructose and glucose are found in grape 




must [17] and $200 \mathrm{~g} \mathrm{~L}^{-1}$ of sugars is considerably higher than the $20 \mathrm{~g} \mathrm{~L}^{-1}$ used in laboratory media, this concentration is at the lower end of typical concentrations found in grape must (240-300 $\mathrm{g} \mathrm{L}^{-1}$ [18]). This compromise was made due to the poorer fermentative ability of laboratory strains in comparison to wine yeast strains [19], in particular the reported sensitivity of S288c derivatives under high osmotic pressure [13]. The assimilable nitrogen content (487 $\mathrm{mg} \mathrm{N} \mathrm{L}^{-1}$ ) was sufficient for complete fermentation of $200 \mathrm{~g} \mathrm{~L}^{-1}$ of sugar and greater than the minimum requirement by yeast $\left(140 \mathrm{mg} \mathrm{N} \mathrm{L}^{-1}\right.$ [15]) and also addressed the auxotrophic requirements of the diploid strain, BY4743, in which the yeast homozygous gene deletion collection was generated [12]. At the study's commencement the lack of availability of a prototrophic yeast deletion collection in either a laboratory yeast [20] or wine yeast genetic background [21] meant that fermentation without the addition of amino acids matched to the auxotrophic requirements of BY4743 could not be investigated. Such an investigation is nonetheless of interest to determine the genetic basis for differences in the nitrogen efficiency of yeast [15].

The initial screen was performed in duplicate $0.6 \mathrm{~mL}$ fermentations at $28^{\circ} \mathrm{C}$ over 7 days in uracil-supplemented CDGJM_200. This medium supported growth of the parental strain BY4743, with all glucose and fructose being consumed within $144 \mathrm{~h}$ (data not shown). The individual fermentation performance of each of the $\sim 5100$ yeast 
clones of the homozygous diploid deletion collection was compared with BY4743 (data not shown; Figure 1). The extent of fermentation was defined by enzymatic determination of the residual glucose and fructose content after $180 \mathrm{~h}$ and was considered complete when the total residual sugar was $<2.5 \mathrm{~g} \mathrm{~L}^{-1}$. The additional $36 \mathrm{~h}$, representing an extra $25 \%$ in fermentation duration, was chosen to allow for growth discrepancies due to the potential for minor differences in inoculation rates. 336 gene deletion mutants were identified as having failed to complete fermentation after $180 \mathrm{~h}$ (Additional file 1).

In order to eliminate the possibility that incomplete fermentation by these 336 deletants was due to impaired growth, micro-fermentations were repeated with the additional estimation of growth (OD $600 \mathrm{~nm}$ ) over the duration of the fermentation (Figure 1 and Additional file 1). Residual sugars in the subsequent experiment were analysed at $137 \mathrm{~h}$ (BY4743 residual sugar $=2.48 \mathrm{~g} \mathrm{~L}^{-1}$ ), and only deletants with optical densities $\left(\mathrm{OD}_{600}\right)$ comparable to BY4743 (i.e. > 70\%) were chosen for further investigation. In such candidates, the corresponding gene deletion was considered to have no or little effect on growth and to more specifically affect fermentation. As such, 101 deletants were chosen as potential candidates dysfunctional in fermentation under high sugar conditions.

\section{Evaluation of deletants in laboratory scale $(100 \mathrm{~mL})$ fermentation}

To test that the fermentation phenotype of the 101 deletants was reproducible in a more controlled environment, the performance of these was compared with the parent strain in larger, $100 \mathrm{~mL}$ fermentations (Figure 1). Fermentations conducted at this scale allow greater control over parameters which influence experimental reproducibility and fermentation outcome, such as inoculum preparation, maintenance of anaerobiosis and the inclusion of biological triplicates. The relative fermentation duration (RFD) of deletant versus parent was recorded in the experimental data (Additional file 1). Seventy two deletants had protracted fermentation, taking $20 \%$ or longer to complete fermentation than the parent. Eight of these were not only protracted but did not complete fermentation (Figure 2) and the fermentations were deemed 'stuck'.

The remaining 29 mutants exhibited fermentation durations similar to the parent ( 14 deletants, $\mathrm{RFD}=1.0 ; 13$ deletants, $\mathrm{RFD}=1.1 ; 2$ deletants, $\mathrm{RFD}<1$ ). These findings indicate that although there was a $29 \%$ over-estimation of genes affecting fermentation in the second screen (where optical density was measured), $71 \%$ of the clones were still identified as affecting fermentation.




The 72 deletants identified as being protracted in fermentation in a high sugar medium (CDGJM_200) were screened as part of the original 336 (Figure 1) in a micro-fermentation of low sugar medium (CDGJM_20) containing $20 \mathrm{~g} \mathrm{~L}^{-1}$ (Additional files 1 and 2). The 72 deletants could be separated into two distinct groups based on two time points at which residual sugar was measured during fermentation: $32 \mathrm{~h}$ (fermentation completed by the parent) and $56 \mathrm{~h}$ (175\% duration). At $32 \mathrm{~h}$, the cut-off of $2.5 \mathrm{~g} \mathrm{~L}^{-1}$ residual sugar was used; 43 deletants were found to have completed fermentation, with 29 deletants having $>2.5 \mathrm{~g} \mathrm{~L}^{-1}$ sugar. At 56 hours all the deletants except $\Delta$ tkl1 had completed fermentation. TKL1 was retained in the 72 gene dataset based on the delay in fermentation when examined in $100 \mathrm{~mL}$ scale using CDGJM_200.

\section{Use of the FRYG databases to identify genes which} modulate fermentation - the 'Fermentome'

Two FRYG databases (Fermentation Relevant Yeast Genes) were separately compiled from previously published fermentation relevant studies and the Saccharomyces Genome Database (Additional file 3). The databases were complementary; the first (LIT_FRYG) was derived from relevant literature, examining single stress conditions related to fermentation. The second (SGD_FRYG), was compiled from fermentation relevant phenotype terms specifically selected from the more general SGD phenotype terms database, whereby only null mutants (deletants) with a specific phenotypic response, i.e. decreased resistance or increased sensitivity were selected. The 72 gene dataset (representing the remaining candidates following $100 \mathrm{~mL}$ fermentations) was compared to the two FRYG databases in order to determine which were previously reported (Figure 1). The SGD_FRYG database was more inclusive with 65 out of the 72 genes being previously reported in related conditions whilst only 55 out of the 72 genes were identified in the LIT_FRYG database.

GO analysis of the identified 72 fermentation essential genes highlighted specific biological processes and more importantly, the other gene members for each GO term, that are likely to be important for fermentation. To ensure that these related genes were not incorrectly excluded as 'false negatives' they were re-examined here in a follow up screen. Of the 29 mutants examined, 21 gave protracted fermentation in CDGJM_200.

One of these, $(\Delta \operatorname{tps} 1)$ did not finish fermentation and was considered 'stuck' (Figure 2 and Additional file 2). The 21 genes were cross-referenced to both FRYG datasets (Additional file 3). The genes absent from the databases are shown in Table 1.

In summary, 93 genes were identified as being required for fermentation, whereby deletion of the gene resulted in the yeast undergoing protracted fermentation
Table 1 Fermentation essential genes shown to be absent in either LIT_FRYG or SGD_FRYG databases

\begin{tabular}{lll}
\hline $\begin{array}{l}\text { FEGs absent in } \\
\text { LIT_FRYG }\end{array}$ & $\begin{array}{l}\text { FEGs absent } \\
\text { in SGD_FRYG }\end{array}$ & $\begin{array}{l}\text { FEGs absent in LIT_FRYG } \\
\text { and SGD_FRYG }\end{array}$ \\
\hline DUF1 (YOL087C) & HRK1 (YOR267C) & CCZ1 (YBR131W) \\
GPA2 (YER020W) & CYK3 (YDL117W) & ATG7 (YHR171W) \\
NHX1 (YDR456W) & & HXK1 (YFR053C) \\
OP11 (YHL020C) & & PUG1 (YER185W) \\
PUG1 (YER185W) & & RXT3 (YDLO76C) \\
RBL2 (YOR265W & & YFL012W \\
RTT103 (YDR289C) & & CIS1 (YDR022C) \\
TOM1 (YDR457W) & & SNX4 (YJL036W)
\end{tabular}

VAC8 (YELO13W)

$Y L L O O T C$

ZAP1 (YJLO56C)

GPR1 (YDLO35O

OPI1 (YHLO20C)

The 93 FEG dataset identified after the fermentation screen and GO analysis depicted in Figure 1, was compared with the LIT_FRYG and SGD_FRYG databases (see Additional file 3 to determine which genes were absent and thus unique to this study).

in CDGJM_200 (Additional file 2). Together, the 93 genes, are referred to as the FEG dataset (for Fermentation Essential Genes) and comprise the laboratory yeast 'fermentome'; genes that are essential for the timely completion of fermentation. The 'fermentome' is taken to represent the genes/processes required for yeast to sense and respond to the multiple stresses of the juice environment. These cellular processes enable yeast to grow in grape juice and complete fermentation over the extended period of 4-12 days typical of a wine fermentation. The experimental design however did not allow for the identification of genes whose deletion shortened fermentation, as no time point was taken prior to the parent finishing. Independent studies have identified genes which affect carbon and nitrogen flux and thus positively modulate fermentation, although the mechanisms remain unclear. For example the genes NGR1 and GID7, upon disruption, resulted in enhanced catabolism of sugar in a wine and laboratory strain during growth in CDGJM_200 with limiting nitrogen [22]. Also, deletion of $P D A 1$, encoding the pyruvate dehydrogenase E $\alpha$ subunit, was shown to alter carbon flux during anaerobic fermentation, resulting in shortened fermentation, after an extended lag phase $(12 \mathrm{~h})$, which the authors suggested was an acclimatisation to the fermentation conditions [23].

The studies chosen to build the LIT_FRYG dataset included those examining growth in response to a single stress relevant to wine fermentation [3-11,24-26] as well as a transcriptomic study of the wine strain Vin 13 during fermentation of a Riesling juice [27]. Our dataset represents only a small percentage of the genes identified in the 
above studies, as shown in LIT_FRYG (Additional file 3), relating to growth sensitivity as a measure of stress tolerance. Not surprisingly, the largest representations relate to hypertonic conditions (21.4\%) [24], high glucose (17\%) [4], ethanol $(8.3 \%$ [9], 18.4\% [9], 14.9\% [10]), anaerobic growth (13.6\% [26], 8.3\% [5]) and sucrose (9.9\%) [3] - see Additional file 3. The importance of experimental design is highlighted by the fact that our study contained only $1.79 \%$ of genes described as Fermentation Stress Response (FSR) genes [27]. Although Marks and co-workers [27] looked at gene expression in response to increasing ethanol concentration during fermentation, small changes in transcript levels of FSR may not eventuate in altered fermentation kinetics or outcome - a more likely observation with complete deletion as per our study. A similar conclusion was drawn from data relating to growth rate and stress tolerance [28], whereby the authors examined the yeast deletion collection in continuous culture.

Eighteen of the 93 genes, which resulted in protracted fermentation when deleted, were annotated to vacuole function, specifically the vacuolar $\mathrm{H}^{+}$ATPase complex. Within this dataset, 6 genes were identified by relationship rather than in the original fermentation screen (72 gene dataset) due to clonal errors within the library used in the study. New clones were sourced (Invitrogen) and verified by sequencing prior to analysis (100 $\mathrm{mL}$ scale). The occurrence of 10 of these genes in the freeze thaw stress dataset (VMA1, VMA2, VMA3, VMA4, VMA7, VMA8, VMA11, VMA13, VPH1 and VPH2) [29] indicates that cellular mechanisms required for tolerance to freeze-thaw stress [29] may also be needed for successful fermentation. By comparison of our results to previous studies (see Additional file 3), we propose that the role of the vacuole, specifically maintenance of vacuolar acidification (discussed later) is a key mechanism of cellular response and adaptation during the transitory and dynamic stress conditions imposed by acidic $\mathrm{pH}$, high osmolarity (sugar, organic acids), increasing ethanol content and elevated temperatures during fermentation.

The association between cross-tolerance to multiple stresses and fermentation outcome, as well as fermentative growth and stress tolerance was examined. Genes common to the FEG dataset and selected datasets from the SGD_FRYG database can be highlighted (Figure 3A-F). Here only 83 fermentation essential genes are compared as the additional 10 (of the 93) unique to our study are necessarily excluded. Of particular interest was the large number of genes, when deleted, were associated with decreased resistance to multiple stresses: ethanol, acidic and hyper-osmotic conditions and heat (for example DOA4 (YDR069C), PLC1 (YPL268W), TPS2 (YDR074W), and SSQ1 (YLR369W) as shown in Additional file 3).

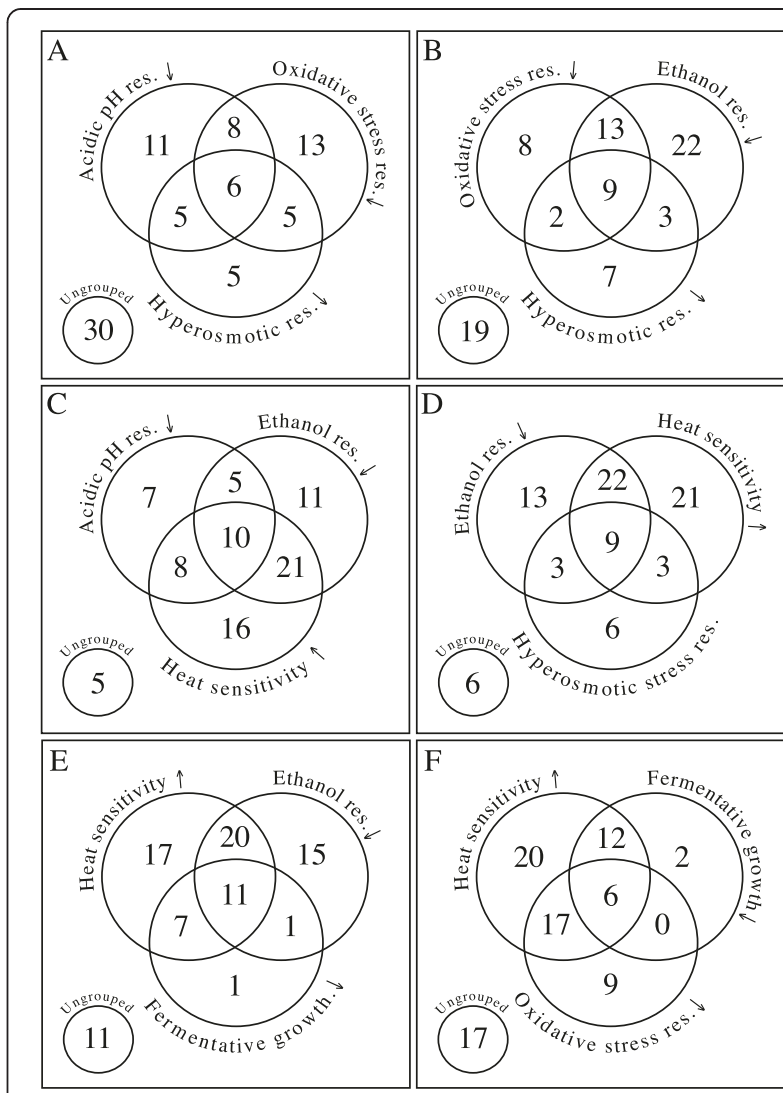

Figure 3 Comparison of fermentation essential genes with the SGD_FRYG database: phenotypic response to specific stress conditions. Ninety three fermentation essential genes (FEG) were identified in this study. Ten of the genes have not been previously associated with fermentation related phenotypes and are unique to this fermentation study. The Venn diagrams therefore depict the number of genes within the 83 FEG dataset which upon deletion, leads to either increased sensitivity or decreased resistance to conditions relevant to fermentation, such as anaerobic growth, ethanol toxicity, osmotic and oxidative stress and temperature extremes.

Yeast deletants encoding the vacuolar $\mathrm{H}^{+}$ATPase (vma mutants) were often associated with cross tolerance towards several stress conditions but not necessarily fermentative growth. Surprisingly, none of the 83 gene deletions were associated with decreased utilisation of nitrogen and fermentative metabolism (Additional file 3).

\section{Classification of genes into specific gene ontology categories}

Using GO toolbox [30] and GO module [31] the Fermentation Essential genes (FEG) were classified into distinct groups according to GO terms, based on their role in a biological process, function within the cell and cellular localisation (Additional file 4). The frequency of occurrence within the genome of genes annotated to these 
GO terms was compared to the frequency of occurrence of genes within the FEG dataset annotated to these same terms. An increased frequency of occurrence (an enrichment) of genes in the FEG dataset annotated to a specific GO term implies the importance of that GO cluster to fermentation completion.

A subset of the most enriched GO terms $\left(p=10^{-31}\right.$ to $10^{-13}$ ) includes gene clusters related to vacuolar function and cellular $\mathrm{pH}$ and ion homeostasis (Figure 4). The vacuole has a multifunctional role; trafficking of membrane proteins to the plasma membrane, proteolytic degradation and recycling of proteins sent to the vacuole [32], sequestration of toxic metal ions, ion homeostasis (calcium and phosphate), osmo-regulation $\left(\mathrm{Na}^{+} / \mathrm{K}^{+}\right.$accumulation) and storage of amino acids [33]. Disruption of these functions can therefore have far reaching consequences for a cell grown at high osmolarity and low $\mathrm{pH}$ conditions.
Incomplete 'stuck' fermentation as a result of deletion of specific genes

Nine deletants within the 93 gene FEG dataset gave rise to incomplete (stuck) fermentations (Figure 2). These genes are central to ion homeostasis (PTK2 (YJR059W)), SSQ1 (YLR369W)), NAD recycling (NPT1 (YOR209C)), signalling (PLC1 (YPL268W)), trehalose synthesis (TPS1 (YBR126C), TPS2 (YDR074W)), transcription (SIN3 (YOL004W), ZAP1 (YGR285C)), and ubiquitin recycling (DOA4 (YDR069C)). With the exception of $\Delta$ tps1 and $\Delta$ ptk2, which showed normal growth, the other 7 'stuck' mutants exhibited reduced biomass (as determined by maximum $\left.\mathrm{OD}_{600}\right)$. Our findings are only in part comparable to the SGD database where $\Delta$ tps $1, \Delta$ tps $2, \Delta$ npt1, $\Delta$ plc1, and $\Delta$ ssq1 were shown to have reduced fermentative growth (Additional file 3 and Table 2). Underlying these differences is likely the experimental approach used. It is evident that final biomass (maximal $\mathrm{OD}_{600}$ )



Figure 4 Enrichment of FEG annotated to specific GO terms from SGD using GO ToolBox GO-Stats. The frequency of gene occurrence (expressed as a percentage) for individual GO terms was compared between the 93 FEG dataset and the entire yeast genome (7168 genes). These GO terms were not mutually exclusive. The statistical probability was calculated to determine the enrichment of the specific GO terms, expressed as $p$-values. Numbers in brackets represent the number of genes in FEG annotated to a specific GO term. Data from the yeast genome is denoted with $\square$ and the FEG dataset (93 genes) with $\mathbf{m}$ 
Table 2 SGD_FRYG fermentation phenotypes associated with nine 'stuck fermentation' mutants

\begin{tabular}{|c|c|c|c|c|c|c|}
\hline $\begin{array}{l}\text { Acidic } \mathrm{pH} \\
\text { resistance }\end{array}$ & $\begin{array}{l}\text { Hyperosmotic } \\
\text { stress resistance }\end{array}$ & $\begin{array}{l}\text { Oxidative stress } \\
\text { resistance }\end{array}$ & $\begin{array}{l}\text { Cold } \\
\text { sensitivity }\end{array}$ & $\begin{array}{l}\text { Heat } \\
\text { sensitivity }\end{array}$ & $\begin{array}{l}\text { Starvation } \\
\text { resistance }\end{array}$ & $\begin{array}{l}\text { Ethanol } \\
\text { resistance }\end{array}$ \\
\hline & SSQ1 & SSQ1 & SSQ1 & SSQ1 & & SSQ1 \\
\hline TPS2 & TPS2 & TPS2 & & TPS2 & & TPS2 \\
\hline \multirow[t]{4}{*}{ DOA4 } & DOA4 & DOA4 & & DOA4 & & DOA4 \\
\hline & $P L C 1$ & $P L C 1$ & & $P L C 1$ & & PLCl \\
\hline & & PTK2 & & & PTK2 & PTK2 \\
\hline & & NPT1 & & NPT1 & & \\
\hline \multirow[t]{2}{*}{ TPS1 } & & & & & & TPS1 \\
\hline & & & & SIN3 & & SIN3 \\
\hline ZAP1 & & ZAP1 & & & & \\
\hline
\end{tabular}

Phenotype responses which result in decreased resistance are denoted with a downward $(\downarrow)$ arrow, whilst those which result in increased sensitivity are denoted with an upward $(\uparrow)$ arrow.

does not necessarily determine whether yeast are able to catabolise sugar albeit in an extended time frame (protracted) or fail to catabolise all of the sugar (defined as a stuck fermentation). Four vma mutants (defective in vacuolar ATPase) that had a similar growth deficiency (plus an extended lag phase) were able to catabolise sugar albeit more slowly than the parent BY4743 (Figure 5).

All 9 genes associated with stuck fermentations were shown to have increased sensitivity towards multiple stresses relevant to fermentation (Table 2 and Additional file 3), with DOA4, SSQ1 and TPS2 being associated with five stresses. Interestingly, only SIN3, SSQ1, TPS1 and TPS2 genes were associated with 'response to stress' GO:0006950 (Additional file 4) although there was no over-representation within the FEG dataset for genes annotated to this GO term. Whilst $\Delta$ plc1 results in decreased glucose utilisation, none of the 9 stuck mutants are listed as decreased fermentation metabolism, decreased nitrogen utilisation or decreased anaerobic growth (Additional file 3).

\section{Role of TPS1 and TPS2 as protectants against multiple stresses}

TPS1 (trehalose-6-phosphate synthase) and TPS2 (trehalose-6-phosphate phosphatase) are required for trehalose biosynthesis and not surprisingly were both identified in this study as FEGs. Deletion of either TPS1 or TPS2 leads to complete cessation of sugar utilisation in the second half of fermentation i.e. a 'stuck' fermentation (Figure 2). Trehalose, a non-reducing disaccharide, ordinarily accumulates during stationary phase and is classified as a storage carbohydrate [34]. It is associated with increased survival and cell protection from stresses such as heat, ethanol and freezing [35]. Accordingly, trehalose protects against lipid peroxidation and protein carbonylation resulting from ethanol induced oxidative stress, which would otherwise impact on membrane dynamics and glycolysis, respectively [36].
Past studies have shown sensitivity of $\Delta$ tps1 to ethanol [10] and oxidative stress [6], and $\Delta$ tps 2 to ethanol, heat, and $\mathrm{NaCl}$ [24], high acidity [25] and oxidative stress $[6,24]$. Conversely, over-expression of these genes results in enhanced thermotolerance and improved ethanol resistance [35-37]. Given the recent link between mitochondrial mutation and ageing [38], and trehalose [36], and that fermentation is conducted by metabolically active but stationary phase cells, it is likely that the lack of trehalose in $\Delta$ tps 1 and $\Delta$ tps2 [36] results in a vastly decreased ability of the cell to protect against the toxic effect of ethanol, leading to increased mitochondrial dysfunction and premature ageing and reduced viability during fermentation.

\section{Role of SIN3 in thermal stress}

Adaptation to elevated temperatures, especially above $30^{\circ} \mathrm{C}$ and in the presence of ethanol [39], is fundamental to survival and the ability to complete fermentation. The primary mechanism is the heat shock response operating through chromatin modulation by the Rpd3L deacetylase complex, which is recruited to target promoters upon heat stress affecting transcription and general metabolic processes (reviewed in [40]). SIN3 is associated with the heat shock response; deletion of which resulted in the complete arrest of fermentation (Figure 2). Sin3p is a component of the Rpd3L complex, along with Sap30p and Rxt3p. The latter two genes, when deleted, resulted in only protracted fermentation. The Rdp3L complex is proposed to facilitate the ability of yeast to tolerate multiple stresses including thermal and osmotolerance but not oxidative stress [28].

\section{SSQ1 and ZAP1 in ion homeostasis}

Osmotic stress, whether salt or sugar induced, is well known to have a direct effect on cellular ion homeostasis [41]. In response to the external environment, various transporters transport cations into the organelles and across the plasma membrane, such that cell turgidity is 

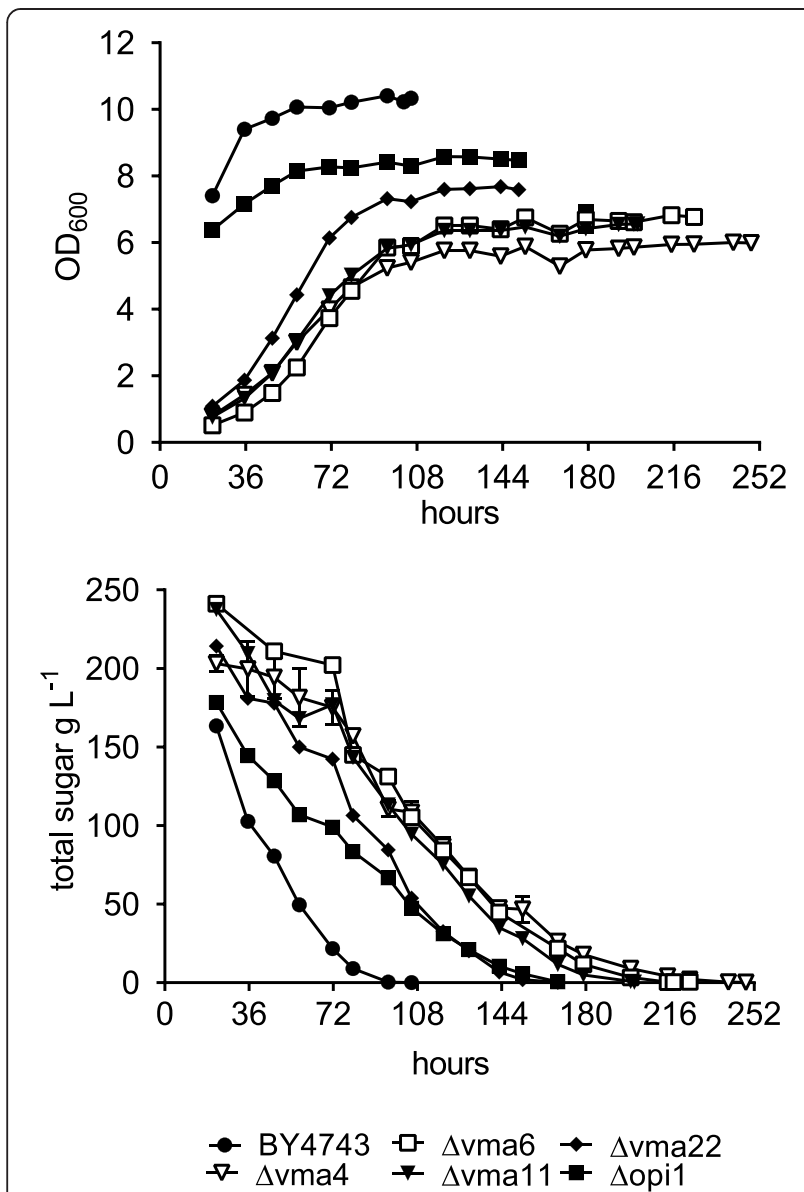

Figure 5 Comparative fermentations with parent yeast BY4743 and four $\Delta$ vma mutants and $\Delta$ opi1 in CDGJM_200.

Fermentations (100 mL) were performed in triplicate in CDGJM_200 at $28^{\circ} \mathrm{C}$ whereby the deletants were compared directly with the parental strain BY4743. Fermentation progress was monitored by determining the total residual sugar (glucose and fructose) by enzymatic analysis. Growth was monitored as optical density $(600 \mathrm{~nm}) 20 \mathrm{~h}$ post-inoculation and at intervals throughout fermentation.

maintained [42]. In this study 26 genes (28.9\% of FEG genes) involved in ion homeostasis were identified as having a role in fermentation.

Two FEGs in particular, SSQ1 and ZAP1, involved in iron and zinc homeostasis respectively, resulted in 'stuck' fermentation (Figure 2). SSQ1 encodes a mitochondrial hsp70-type molecular chaperone that is required for the assembly of Fe-S clusters into Fe-S proteins, such as the mitochondrial proteins aconitase, Yfh1p and several DNA repair enzymes [43]. Iron homeostasis is proposed to be highly regulated, with the Fe-S clusters thought to function as regulatory sensors to oxidative stress and intracellular iron (reviewed in [43]). Yeast strains lacking the Fe-S cluster scaffold protein Isu1p or chaperone protein Ssq1p increase iron sequestration to the mitochondria, and show increased mitochondrial oxidative damage
[43]. Transcription of ISU1 was altered during fermentation in response to increasing external ethanol content [27], however, in this study $\Delta$ isul had comparable fermentation duration to the parent (microferment 1; see Additional file 1). Given the speculation on Fe-S proteins acting as iron sensors, decreased formation of these proteins as observed in $\Delta$ ssq1 [44] may lead to a signalling of iron deficiency within the mitochondria. This may cause an increase in mitochondrial uptake and decrease in export of iron, and consequently mitochondrial iron overload and subsequent oxidative damage. $\Delta$ ssq1 has been previously shown to be sensitive to oxidation [44], which may explain the fermentation phenotype of $\Delta$ ssq 1 in our study, in terms of oxidative stress associated with fermentation in CDGJM_200 and the low iron content $\left(14 \mu \mathrm{g} \mathrm{L}^{-1}\right)[17,45]$, which is in the lower range (20-330 $\left.\mu \mathrm{g} \mathrm{L} \mathrm{L}^{-1}\right)$ of typical Australian Chardonnay juices [46]. Given that mitochondrial dysfunction has recently been linked with vacuolar acidification in affecting chronological ageing [38] it is of interest that the $\Delta$ ssq1 deletant is not defective in vacuolar acidification ([47], data not shown).

It appears that zinc homeostasis is also critical to fermentation, through the transcriptional control of some 80 genes exerted by the zinc-sensing transcription factor Zap1p, (reviewed in [48]). These include genes involved in phospholipid biosynthesis, zinc uptake and vacuolar storage (detoxification), sulfur metabolism, cell wall function and response to oxidation (ROS) [48]. Zap1p has a protective role with regards to oxidative stress and damage. The down-regulation of sulfur metabolism by Zap1p in zinc deficient cells is associated with increased protection through the redirection of NADPH from sulfur metabolism to regenerating reduced peroxiredoxin and glutathione associated with antioxidant defence mechanisms (cited in [48]). The extended and incomplete fermentation profiles of $\Delta$ zap1 (Figure 2) indicate that Zap1p's role as a core regulatory protein particularly in oxidative protection and perhaps vacuolar storage is vital for fermentation maintenance.

\section{Influence of intracellular $\mathrm{pH}$ on fermentation}

GO analysis of the FEG dataset (Additional file 4), not only highlighted the enrichment of 18 genes associated with the vacuolar $\mathrm{H}^{+}$ATPase complex (targeted by Vph1p isomer of $\mathrm{V}_{0}$ subunit a) [49-51] but also $D B F 2$ (YGR092W) [52] and NHX1 (YDR456W) [53], known to be involved with regulation of intracellular $\mathrm{pH}$. The tight regulation of intracellular $\mathrm{pH}$, whilst influenced by external $\mathrm{pH}$ and nutrient availability, is reflective of most physiological processes being $\mathrm{pH}$ dependent [48]. Critical to this, is the cytosol's buffering capacity, originating from the acid-base action of metabolites such as ammonium, phosphate and carbon dioxide, as well as proteins 
[54]. As such, pH 'sensing' is associated with many processes including carbon flux through the glycolytic cycle, coupled reduction-oxidation reactions involved in $\mathrm{NAD}(\mathrm{P})^{+}$cycling as well as phosphatidylinositol phosphates acting as signalling molecules to effect transcription [54].

The main $\mathrm{pH}$ regulator in yeast is a $\mathrm{P} 2$ type $\mathrm{H}^{+}$ATPase; Pma1p, responsible for the active translocation of protons across the plasma membrane into the external medium, thus maintaining cytosolic $\mathrm{pH}$ at neutral $[48,55]$. The second, is the vacuolar $(\mathrm{V}) \mathrm{H}^{+}$ATPase, a complex of two domains, $V_{1}$ (8 subunits) and $V_{0}$ (6 subunits), which is responsible for the active transport of protons from the cytosol into the vacuolar lumen [49]. PMA1 (YGLO08C) is an essential gene and so not present in the homozygous diploid deletion library used in this study. However, the

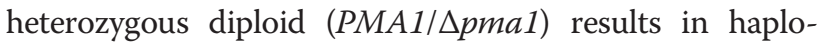
insufficiency, i.e. reduced growth rate in grape juice conditions (202 $\mathrm{mg} \mathrm{L}^{-1}$ YAN, $130 \mathrm{~g} \mathrm{~L}^{-1}$ water soluble carbohydrate (WSC)) and surprisingly also the reverse, haploproficiency (increased growth rate) in nitrogen and carbon limiting conditions $\left(118.7 \mathrm{mg} \mathrm{L}^{-1}\right.$ YAN, $2.5 \mathrm{~g} \mathrm{~L}^{-1}$ WSC) [56].

Pma1p activation is dependent on a complex interaction between glucose sensors such as Snf3p and Rgt2p, and the Gpr1p/Gpa2p receptor/G protein-coupled (GPCR) complex [57], protein kinase C (Pkc1p) [57], phospholipase $\mathrm{C}$ (Plc1p) [58], the proteosome, and interaction with tubulin (as reviewed in [54]). Several studies conducted on glucose starved cells, using specific inhibitors of Plc1 (3-nitrocourmarin) [59,60] and Pma1p (carbonyl cyanide m-chlorophenylhydrazone; CCCP) [61] in conjunction with glucose additions (up to $100 \mathrm{mM}$ or $18 \mathrm{~g} \mathrm{~L}^{-1}$ ) have demonstrated the activation of Pma1p to be mediated by Plc1p and the GPCR complex. Plc1p is proposed to transduce the glucose signal, through calcium signalling, by the induction of calcium uptake into the cell and vacuolar transport into the cytoplasm [59,62-64] Gpr1p aids rapid adaption to extracellular glucose (and not fructose), via the cAMP-PKA pathway [65]. The latter activates cAMP signalling via a glucose phosphorylation mechanism [66].

In this study genes associated with hexose sensing were identified; GPA2 (YERO20W) and GPR1 (YDLO35C)), together with ASC1 (YMR116C) and HXK1 (YFR053C), whose deletion was shown to induce protracted fermentation (Additional files 1 and 4). Hxk1p, which is associated with heat shock response, is one of three protein kinases (Glk1p, Hxk1p, and/or Hxk2p) required for glucose phosphorylation, as a means of intracellular signalling via Gpr1p-Gpa2p. Whilst Asc1p, a guanine dissociation inhibitor of Gpa2p, links glucose metabolism to nitrogen metabolism, as it represses Gcn4p when amino acids are sufficient [66].
PLC1 (YPL268W) was also identified in the FEG dataset (Additional files 1 and 4 ). The inability of the $\Delta$ plc deletant to complete sugar catabolism, as shown in Figure 2 alludes to the importance of Plc1p in cellular metabolism; although the physiological roles during fermentation are not well understood. Plc1p has been implicated in nutrient induced signal transduction via the Gpr1p-Gpa2p mediated GPCR system, coupling glucose and nitrogen signalling at the sensor level [64,67], as well as controlling the MAP kinase cascade via activation of Pkc1p. This cascade is essential to adaptation to high osmolarity and cell wall integrity [41]; obvious important attributes for successful fermentation.

HRK1 (YOR267C) and PTK2 (YJR059W) were also identified and encode protein kinases responsible for the activation of Pmalp in response to glucose [68]. The membrane potential generated by Pma1p is modulated by the uptake of potassium $\left(\mathrm{K}^{+}\right)$by the Trk1p and Trk2p transporters; allowing for different voltage sensitive transporters to function in cation transport $[48,68]$. The central role of $\mathrm{pH}$ (and cation) homeostasis in fermentation is further supported by the inclusion of TRK1 (YJL129C) in the FEG dataset, which encodes the high affinity $\mathrm{K}^{+}$transporter and is also found to be important for resistance to high-glucose [4] and high acidity [25].

Interestingly, Pma1p activity is reduced in yeast in high sugar fermentation conditions with recovery to normal activity being incomplete upon transfer to low sugar conditions [4]. Teixeira and co-workers [4] propose that vesicle trafficking to the plasma membrane is affected, given the mis-targeting of Pma1p in vma mutants lacking V-ATPase subunits to the vacuole [55]. $\mathrm{pH}$ and ion homeostatic mechanisms via V-ATPase are implicated in both osmotic shock from salt and sugar [4], with VATPase contributing to not only vesicle protein trafficking but intracellular (cytosolic) $\mathrm{pH}$ through the translocation of protons into the vacuolar lumen. NHX1 (YDR456W) encoding the endosomal $\mathrm{K}^{+}\left(\mathrm{Na}^{+}\right) / \mathrm{H}^{+}$exchanger, Nhx1p, was also identified as a FEG in our study. Nhx1p is implicated in regulating vacuolar and cytosolic $\mathrm{pH}$ [55], and is thought to represent an early response to hyperosmotic conditions by the transport of ions into the vacuole [69].

The complex interaction between Pma1p, V-ATPase and other symporters is in part also mediated by the lipid rafts associated with these membrane bound proteins. In a recent study [70] lipid raft integrity of the plasma membrane was implicated in $\mathrm{pH}$ homeostasis and growth. Edelsofine, an anti-tumor lysophosphatidyl choline analog, was shown to alter the organisation of the plasma membrane, resulting in ubiquitination and internalisation of Pma1p to the vacuole, resulting in cytoplasmic acidification [70]. The link between membrane (lipid raft) integrity, intracellular $\mathrm{pH}$, and fermentation phenotype is also inferred from the sensitivity of 
the following FEG mutants to Edelsofine, $\Delta \mathrm{asc} 1, \Delta \mathrm{dfb} 2$, $\Delta$ snf4, $\Delta \sin 3, \Delta \operatorname{trk} 1, \Delta$ vma2, $\Delta$ vma4, $\Delta$ vma5, $\Delta$ vma6, $\Delta \mathrm{vma} 7, \Delta \mathrm{vma} 10, \Delta \mathrm{vma} 11, \Delta \mathrm{vma} 16$ and $\Delta \mathrm{vph} 2$ [70].

\section{Role of vacuolar $\mathrm{H}^{+}$ATPase in fermentation}

As mentioned, 18 genes associated with vacuolar acidification, specifically the vacuolar ATPase complex were identified in this study (Additional file 4 and Table 3).

The vacuolar ATPase complex is the major contributor in regulating organelle $\mathrm{pH}$, specifically between the cytosol and vacuolar lumen [49]. This action is intrinsically connected to cellular ion homeostasis (through the action of anti-porters utilizing the generated membrane potential via a proton electrochemical gradient), as well as proteolytic activation (digestion of autophagasomes during autophagy or vacuolar proteolysis induced by starvation), endocytosis, and vacuole fusion [49,71]. Furthermore, intracellular $\mathrm{pH}$ and $\mathrm{Ca}^{2+}$ ion concentrations as well as direct interaction of the V-ATPase complex with the actin cytoskeleton are implicated in bud formation and polarized growth during cell cycle [50,72]. In relation to the vacuole's lytic function, VAM3 (YOR106W) encoding the syntaxin-like protein Vam3p (a vacuolar t-SNARE) is responsible for the correct trafficking and processing of proteinases $\mathrm{A}, \mathrm{B}$ and carboxypeptidase $\mathrm{Y}$ and maturation of alkaline phosphatase [73]. The relevance of Vam3p to fermentation outcome and tolerance of stress (hyperosmolarity, heat, ethanol and oxidation) is highlighted by the

Table 3 Effect upon fermentation of yeast lacking genes encoding vacuolar $\mathrm{H}^{+}$ATPase complex and associated proteins

\begin{tabular}{|c|c|c|c|}
\hline \multirow[t]{2}{*}{ Gene } & V-ATPase subunit & Function (eight subunit peripheral domain) & $\begin{array}{l}\text { Essential for } \\
\text { fermentation }\end{array}$ \\
\hline & \multicolumn{2}{|l|}{$\mathrm{V}_{1}$ domain } & \\
\hline VMA1 (TFP1) & A & ATP hydrolysis & Yes \\
\hline VMA2 & B & Regulatory, ATP binding?, Actin binding? & Yes \\
\hline VMA5 & C & Stator & Yes \\
\hline VMA8 & $\mathrm{D}$ & Rotor & Yes \\
\hline VMA4 & E & Stator & Yes \\
\hline VMA7 & F & Rotor & Yes \\
\hline VMA10 & G & Stator & Yes \\
\hline \multirow[t]{2}{*}{ VMA13 } & $\mathrm{H}$ & Stator & Yes \\
\hline & $\mathrm{V}_{\mathrm{o}}$ domain & (six subunit integral domain) & \\
\hline VPH1 & a (vph1p) & Proton pore, stator, sorting (vacuole) & Yes \\
\hline STV1 & a (Stv1p) & Proton pore, stator, sorting (golgi/endosome) & No \\
\hline VMA3 (CUP5) & C & Proton pore, rotor (dicyclohexylcarbodiimide binding) & Yes \\
\hline VMA11 (TFP3) & $C^{\prime}$ & Proton pore, rotor & Yes \\
\hline VMA16 (PPA1) & $C^{\prime \prime}$ & Proton pore, rotor & Yes \\
\hline VMA6 & $d$ & Rotor & Yes \\
\hline \multirow[t]{2}{*}{ VMA9 } & e & $?$ & nd \\
\hline & \multicolumn{2}{|l|}{ Assembly Factors } & \\
\hline VPH2 (VMA12) & Vph2p & Integral membrane protein; vacuolar $\mathrm{H}^{+}$ATPase (V-ATPase) assembly & Yes \\
\hline VMA22 & Vma22p & Peripheral membrane protein; vacuolar $\mathrm{H}^{+}$ATPase assembly & Yes \\
\hline VPS3 & Vps3p & $\begin{array}{l}\text { CORVET tethering complex; cytoplasmic protein required for sorting \& processing of soluble } \\
\text { vacuolar proteins, acidification of vacuolar lumen, \& assembly of V-ATPase }\end{array}$ & No \\
\hline \multirow[t]{2}{*}{ PKR1 } & Pkr1p & $\begin{array}{l}\text { V-ATPase assembly factor, functions with other } \mathrm{V} \text {-ATPase assembly factors in ER to assemble } \\
\text { V-ATPase membrane sector }\left(V_{0}\right)\end{array}$ & Yes \\
\hline & \multicolumn{2}{|l|}{ RAVE complex } & \\
\hline SKP1 & Skp1p & $\begin{array}{l}\text { Evolutionarily conserved kinetochore protein; part of SCF ubiquitin ligase complex, CBF3 } \\
\text { complex binding centromeric DNA, \& RAVE complex regulating assembly of V-ATPase }\end{array}$ & nd \\
\hline RAV1 & Rav1p & Subunit of RAVE complex (Rav1p, Rav2p, Skp1p), promotes assembly of V-ATPase & Yes \\
\hline RAV2 & Rav2p & Subunit of RAVE complex, promotes assembly of V-ATPase & Yes \\
\hline
\end{tabular}

Fermentations (100 mL) were conducted in CDGJM_200 as described in Materials and Methods. Deletants which resulted in protracted fermentation were considered essential for fermentation in high sugar media, whilst those which were not affected, were considered non-essential. VMA9 (YCL005W-A) and SKP1 (YDR328C) are not in the homozygous diploid deletion library. SKP1 is an essential gene for growth. nd: not determined. 
protracted fermentation of the $\Delta$ vam 3 mutant (Additional file 1) and growth sensitivity towards these stress parameters (Additional file 2).

The importance of the assembly and function of the V-ATPase complex during fermentation, was highlighted by the number of genes identified (Additional files 4 and Table 3). These encode either the subunits of the $V_{1}$ peripheral membrane and $V_{0}$ integral membrane domains, or the assembly factors including the RAVE complex, which are required for the reversible assembly and disassembly into the free $V_{1}$ and $V_{0}$ domains, in response to glucose $[50,51]$. The assembly of V-ATPase is thought to prevent cytosolic acidification when metabolism is active, as protons are sequestered in the vacuolar lumen by the V-ATPase. This is particularly relevant in high sugar fermentation, when the plasma membrane bound pump Pma1p, the principal regulator of cytosolic $\mathrm{pH}$, is transiently inhibited [4]. As glucose becomes limited, the disassembly of some V-ATPase complexes is thought to conserve ATP, as ATP hydrolysis is absent in the isolated $\mathrm{V}_{1}$ domain. The role of vacuolar ATPase in fermentation is supported by previous research showing deletion of structural genes resulting in growth sensitivity to ethanol [8-10] and hyperosmolarity due to high concentrations of glucose $\left(300 \mathrm{~g} \mathrm{~L}^{-1},[4]\right)$. How these differences relate to the $\mathrm{pH}$-dependent growth of vma (vacuolar membrane ATPase) deletants [50] is unclear. Whilst vma deletants, through the loss of V-ATPase activity, exhibit growth sensitivity at high $\mathrm{pH}(>\mathrm{pH} 7)$ or high extracellular calcium and zinc, and reportedly are unable to grow on non-fermentable carbon sources, they are able to grow under acidic conditions ( $\mathrm{pH} 5.5)$ albeit slower than the wild type $[50,74]$. In this study, the mutants were able to grow in CDGJM_200 (pH 3.5) after an extended lag period yet only reached $60-80 \%$ of the parent biomass (Figure 5). The ability of these cells to grow even in the presence of initially high sugar and acid and later, increasing ethanol, is strong evidence that vacuolar acidification by this enzyme complex is not the only mechanism involved. Yeast possess additional, and yet unidentified independent mechanisms to acidify the endosomal compartments including the vacuole. We have preliminary microscopy data using 6-carboxyfluorescein diacetate which supports this notion. Specifically, early in fermentation (24 h) vacuolar acidification, as anticipated, was reduced in a $\Delta v$ mal mutant compared to the parent BY4743. However, after $72 \mathrm{~h}$ and $125 \mathrm{~h}$, by which time fermentation was progressing well, vacuolar acidification was restored in the mutant (data not shown). Recently, vacuolar acidification, particularly the proton dependent storage of neutral amino acids rather than protein degradation in the vacuole, has also been linked to chronological aging [38]. The authors proposed that age-induced mitochondrial dysfunction is a result of decreased vacuolar acidification in aging mother cells, and the regeneration of vacuolar acidification in budding daughter cells, is coincidental with rejuvenation of lifespan. This network between the vacuole and mitochondria, thought to be mediated by nutrient-sensing pathways such as PKA, Sch9 and TOR [38], is important given that fermentation occurs over an extended time-frame, primarily by stationary phase cells which are progressively aging.

Several proposed mechanisms to maintain vacuolar $\mathrm{pH}$ independent of $\mathrm{V}$-ATPase include passive diffusion and dissociation of weak acids, endocytic internalisation of acid equivalents or Pma1p itself [74], and ammonium ions acting as protonophores after uptake [74]. These mechanisms would enable growth under acidic conditions through $\mathrm{pH}$ equilibration across the plasma membrane and vacuolar membrane, maintaining the intracellular $\mathrm{pH}$ gradient between the cytosol and vacuole, relative to the outside. This process is vital to cell adaption to fermentation associated stresses, and allowing for complete sugar catabolism albeit at a slower rate. Whilst some of these alternative mechanisms may play a role normally in $\mathrm{pH}$ regulation, V-ATPase is the principal proton pump proposed to protect yeast from heat stress [75], alcohol stress $[8,9]$, osmotic stress [4], and acid stress [25] associated with fermentation, as well as against stresses of air-drying [29]. The latter is important in this context since commercial wine yeast is generally supplied as active dried yeast.

Whilst there are a myriad of processes and signalling cascades related to stress response, it is only recently that the inter-relationships are being elucidated. For example V-ATPase and the high-osmolarity glycerol (HOG) response pathway are proposed to function in parallel, as adaptive mechanisms to prevent salt toxicity under salt induced stress [76]. Both pathways are crucial for successful sugar fermentation, with not only vma mutants being identified but also the genes for Hog1p and its activator, Pbs2p. It is possible that communication between such processes as vacuolar acidification (V-ATPase), protein trafficking and turnover, and the TOR and HOG signalling pathways is through inositol-containing lipids in stress response signaling [77], in response to stress adaptation.

\section{Microautophagy and the EGO/GSE complex and fermentation}

MEH1 and SLM4 encode 2 of the 3 subunits of the EGO complex and deletion of either severely affected fermentation in this study (65\% slower than the parent). With the third component, Gtr2p, the EGO complex is a vacuolar membrane-associated protein complex required for activation of microautophagy [78] through its function as an activator of the nitrogen regulatory TORC1 (Tor1p or Tor2p-Kog1p-Lst8p-Tco89p) complex [79]. In this study TCO89 was also identified as a FEG, with $\Delta$ tco89 increasing fermentation duration by $43 \%$. Meh1p 
and Slm4p are also members of the GSE (GAP1 Sorting in the Endosomes) complex, a GTPase complex required for intracellular sorting of Gap1p out of the endosome, for eventual delivery to the plasma membrane [80]. The GSE complex is also composed of two small GTPases (Gtr1p and Gtr2p) and Ltv1p, which do not have a critical role in fermentation (Additional file 1). These findings suggest that MEH1 and SLM4 have a major role in fermentation, through vacuolar acidification (Meh1p), probably through amino acid uptake into the vacuole, microautophagy and protein sorting of Gap1p.

Microautophagy and the EGO/GSE complex have been previously implicated in mechanisms allowing yeast cells to grow under low temperature and high pressure [7]. Abe and Minegishi [7] proposed that the EGO/GSE complex may contribute to cell surface delivery of amino acid permeases under such conditions, given the marked defect in histidine, leucine and lysine uptake in the EGO/ GSE complex mutants $(\Delta \operatorname{gtr} 1, \Delta \mathrm{gtr} 2, \Delta$ meh1 $(\Delta$ egol) and $\Delta \operatorname{sim} 4$ ( $\Delta$ ego3)), upon high pressure and low temperature incubation.

As mentioned, the EGO complex is involved in nitrogen sensing via its activation of the TORC1 complex, such that EGO monitors intracellular levels of leucine and glutamine (reviewed in [79]). The inability to activate TORC1 during fermentation may result in fermentation arrest via several processes in which TORC1 is involved: the regulation of amino acid uptake, early glycolysis or induction of autophagy (reviewed in [79]).

It is known that autophagy is triggered by nutritional stress, specifically carbon and nitrogen depletion, and is induced as a prelude to autolysis in yeast conducting the secondary fermentation of sparkling wine production [81]. Autophagy is critical for fermentation outcome in primary fermentation as shown in our study, with 13 related genes identified as FEGs. In a recent study, Piggott et al. [82] looked at competitive fitness (growth) during a 12-day fermentation of a deletion library pool (S288c) in synthetic grape juice. Autophagy and ubiquitination were enriched in the dataset with respect to reduced fitness. However, our datasets for these GO terms are very different, with only 3 genes in common for autophagy; (ATG7 (YHR171W), SNX4/ATG24 (YJLO36W), CIS/ ATG31 (YDR022C)). Other contradictions were the observations for $\triangle$ doa 4 and $\triangle$ pex1. Deletion of $D O A 4$ (homozygous diploid) did not result in reduced competitive fitness [82], contrary to our findings, whereby $\Delta$ doa4 resulted in stuck fermentation. Another anomaly was the finding that $\Delta$ pex1 (protracted fermentation in our study) resulted in increased fitness [82], implying that fermentation would be either similar to the parent or faster. The recent revelation that autophagy occurs not only during starvation but very early in fermentation [82], in response to as yet unknown stresses, alludes to the importance of the various autophagic responses and would explain the observed protracted fermentation phenotype in such mutants in our study.

It is evident that a number of mechanisms involving a myriad of genes are involved in the adaptive response to the major stressors encountered during high sugar fermentation as such only some of these have been discussed to in this study.

\section{Conclusion}

This study reports on the identification of 93 genes whose deletion leads to fermentations that are protracted (84 genes) or arrested ("stuck"; 9 genes). Together, the 93 genes are referred to as Fermentation Essential Genes, and are representative of the 'fermentome'; a dataset of genes (from laboratory yeast) which modulate fermentation. The importance of the FEG is further supported through their presence in two fermentation relevant databases, LIT_FRYG and SGD_FRYG (Additional file 3), collated as part of this study. These datasets are by no means complete, but will be expanded upon as new datasets become available.

In this study we have built upon the understanding of a group of key genes within fermentation. We have identified several cellular processes essential for response and adaptation to a physiologically stressful environment in yeast, namely maintenance of vacuolar acidification, microautophagy and sugar related signalling. Whilst individual biological processes are alluded to with respect to fermentation, the question remains; how do these different sensors, signals and cellular responses interact with each other? A systems biology approach allows us to look at what appear to be unrelated processes, together as a 'network' or 'matrix', in a holistic approach, as well as the traditional reductionist approach $[2,19]$. By taking such a perspective on wine fermentation, we have gained a better understanding of a fundamental biochemical pathway. This understanding allows design of new industrial yeast strains better suited to specific industrial processes. For example demonstration for the importance of ion homeostasis and intracellular $\mathrm{pH}$ maintenance raises the possibility that Directed Evolution could be used to generate new strains using a low $\mathrm{pH}$ environment as the selective pressure.

\section{Methods}

\section{Yeast strains and media}

This study used the collection of yeast diploid deletion strains developed by the Yeast Genome Deletion Project [12]. The homozygous ( $\Delta$ orf::KanMX4) gene deletions were harboured in BY4743 (MATa/a, his3 $\Delta 1 /$ his $3 \Delta 1$, leu $2 \Delta 0 /$ leu $2 \Delta 0$, lys $2 \Delta 0 / L Y S 2$, MET15/met $15 \Delta 0$, ura $3 \Delta 0 /$ ura $3 \Delta 0$ (BY4741/BY4742)). Strains were maintained on 
YPD (1\% yeast extract, 2\% bactopeptone, 2\% D-glucose) containing $200 \mathrm{mg} \mathrm{L}^{-1}$ geneticin (G418 sulfate; Amresco).

Chemically defined grape juice medium containing $200 \mathrm{~g} \mathrm{~L}^{-1}$ sugar as equimolar amounts of glucose and fructose (high sugar; CDGJM_200) and $450 \mathrm{mg} \mathrm{L}^{-1}$ FAN as a mixture of amino acids and ammonium chloride $[17,45]$ was used. The CDGJM_200 was supplemented with $150 \mathrm{mg} \mathrm{L}^{-1}$ uracil, and included $3 \mathrm{~g} \mathrm{~L}^{-1}$ polyphenol extract (Cat: Tppr, OenoProd, Sarl), which was dissolved in $100 \%$ ethanol ( $3 \mathrm{~g}$ powder in $5 \mathrm{~mL}, 24 \mathrm{~h}$, in dark) prior to being added to the sterile medium. The CDGJM _200 was stored in the dark for a maximum of $24 \mathrm{~h}\left(4^{\circ} \mathrm{C}\right)$ before use. CDGJM_20 was identical to CDGJM_200 except that the sugar concentration was decreased to $20 \mathrm{~g} \mathrm{~L}^{-1}$ (low sugar; CDGJM_20).

\section{Genome-wide screening for yeast deletants with protracted fermentation in high sugar media (CDGJM_200)}

Liquid handling of the samples was performed using a CAS3800 robot (Corbett Robotics, Sydney). The library was replicated $(6 \mu \mathrm{L})$ into $0.6 \mathrm{~mL}$ YPD in 96 deep-well plates (Cat: P-DW-20-C, Pacific Lab Products) and incubated $24-48 \mathrm{~h}$ at $28^{\circ} \mathrm{C}$ in a humidified box without shaking. Each plate had 11 rows (A1-11 to H1-11) containing single samples of the deletion strains and four replicates each of the parental strain, BY4743 (A12-D12) and uninoculated controls, CDGJM_200 (E12-H12). Cells were resuspended by agitation on a mini-vortexing-shaker and $6 \mu \mathrm{L}$ was inoculated into $0.6 \mathrm{~mL}$ CDGJM_200 in 96 deep-well plates and covered with breathable sealing film (Cat: BF-400, Adelab Scientific). The initial fermentation screen was performed in duplicate in humidified boxes. After $180 \mathrm{~h}$ at $28^{\circ} \mathrm{C}$, the cells were pelleted by centrifugation $(1620 \mathrm{x} \mathrm{g}, 5 \mathrm{~min})$ and $0.2 \mathrm{~mL}$ supernatant samples were dispensed into 96 well flat bottomed plates (Cat: P96-300 F-PS, Adelab Scientific) and frozen at $-20^{\circ} \mathrm{C}$ for subsequent sugar analysis. Residual glucose and fructose were quantified enzymatically using a commercially available kit (Cat: 139106, Boehringer Mannheim) adapted for 96-well plates. The total volume of the reaction was reduced from $1.62 \mathrm{~mL}$ to $0.125 \mathrm{~mL}$. Three times the concentration of the reaction buffer was used to provide NADP and ATP to excess, and to ensure accurate pipetting, $10 \mu \mathrm{L}$ of a 1:10 dilution of the enzymes in MQ water was used (as opposed to $1 \mu \mathrm{L}$ ). The samples were diluted 1:10 (for $<20 \mathrm{~g} \mathrm{~L}^{-1}$ ) and 1:100 (for $>20 \mathrm{~g} \mathrm{~L}^{-1}$ ) and determined against a set of identically diluted standards which were within the linear range of the reaction $(0-0.08 \mathrm{~g} \mathrm{~L}$ $\left.{ }^{-1}\right)$. Absorbance at $340 \mathrm{~nm}$ was measured using a $\mu$ Quant microplate spectrophotometer (Bio-Tek Instruments).

A second experiment ( $c f$ initial screen) was conducted, using a sacrificial plate method [83] on the 336 deletion strains identified as having protracted fermentation.
At specific time points during fermentation (41, 89, 113, 137 and $190 \mathrm{~h}$ ), a replicate plate was sacrificed to measure growth $\left(\mathrm{OD}_{600}\right)$ and residual sugar in the CDGJM_200 media. Absorbance was measured using a microplate spectrophotometer.

Low sugar fermentations were also conducted on the 336 deletants (cf second screen) using CDGJM_20, in which the sugar content was reduced to $20 \mathrm{~g} \mathrm{~L}^{-1}$ and the duration of the fermentation was $56 \mathrm{~h}$. Growth and fermentation progress was monitored as previously described at two time points: 32 and $56 \mathrm{~h}$.

\section{Evaluation of identified yeast deletants in laboratory scale (100 mL) fermentations in CDGJM_200}

Triplicate $100 \mathrm{~mL}$ fermentations were performed in CDGJM_200 using $250 \mathrm{~mL}$ Erlenmeyer flasks fitted with airlocks [84]. $\mathrm{N}_{2}$ sparging was omitted as previous studies demonstrated that anaerobic conditions were achieved within 4-6 hours of fermentation commencement (data not shown). Fermentation progress was monitored by refractive index ( ${ }^{\circ}$ Brix). Fermentations were considered dry and terminated when the residual sugar was less than $2.5 \mathrm{~g} \mathrm{~L}^{-1}$ as determined by Clinitest ${ }^{\mathrm{TM}}$ (Cat: 2107, Bayer). Residual glucose and fructose were determined by enzymatic analysis as described above.

\section{Confirmation of the identity of yeast deletants}

Gene deletions in the 93 FEG (Fermentation Essential Genes) yeast clones were confirmed by PCR amplification of deletion cassettes from isolated genomic DNA using the protocol described in the Saccharomyces Genome Deletion Project (http://www-sequence.stanford. edu/group/yeast_deletion_project/deletions3.html). The PCR products of select clones were verified by DNA sequencing (AGRF, Adelaide).

\section{Classification and numeric enrichment of identified genes annotated to Gene Ontology (GO) terms using computational software tools}

The datasets were analysed using GOToolBox; specifically GO-Stats (http://genome.crg.es/GOToolBox/) [30] and GO Finder Version 0.83 software (http://www.yeast genome.org/cgi-bin/GO/goTermFinder.pl) which allowed the hierarchical clustering and over-representation (enrichment) or under-representation (depletion) of genes based on shared Gene Ontology (GO) terms. Both computational tools use a hypergeometric distribution with Multiple Hypothesis (Bonferroni) Correction (and additional False Discovery Rate; GO Finder) to calculate $p$ values. The clustering of genes based on their shared gene annotations was also determined using GO-Proxy (http:// genome.crg.es/GOToolBox/) and/or SGD Gene Ontology Slim Mapper (http://www.yeastgenome.org/cgi-bin/GO/ goSlimMapper.pl). 
The interpretation of the GO terms identified was simplified using the web-based visualisation tool GOModule (http://lussierlab.org/GO-module) [31]. GO biomodules are 'nodes' which represent the key GO terms (K nodes) and their hierarchical descendents which are considered true-positive GO terms ( $\mathrm{T}$ nodes). False positive prioritized GO terms in the input data are identified as F nodes.

Two databases denoted Fermentation Relevant Yeast Genes (FRYG), were compiled from data available on the Saccharomyces Genome Database (http://www.yeast genome.org/) and from a literature survey. The databases referred to as SGD_FRYG and LIT_FRYG were used in comparison studies. Statistical analysis of the results was performed using a hyper geometric algorithm as described by Martin et al. [30] to determine whether there was an enrichment (over representation) of genes identified in this study when compared to the FRYG datasets.

\section{Availability of supporting data}

The data set supporting the results of this article is available in the LabArchives repository, under Fermentation Microbiology doi:10.6070/H4057CW1 and hyperlink to dataset(s) in https://mynotebook.labarchives.com/share/ Fermentation\%2520Microbiology/MjQuN3w0MDY2Ni 8xOS9UcmVlTm9kZS8xMzY5ODkyMTYxfDYyLjc $=$.

The data set supporting the results of this article is included within the article (and its additional file(s)).

\section{Additional files}

Additional file 1: Experimental data from micro-scale and laboratory-scale fermentations in chemically defined grape juice medium. Micro-fermentation screens 1 and 2 were conducted in high sugar media (CDGJM_200) whilst micro-fermentation 3 was conducted in a low sugar medium (CDGJM_20). Values were the average of duplicate fermentation samples per strain. Laboratory scale $(100 \mathrm{~mL})$ fermentations were performed in CDGJM_200, and the values represent the average of triplicate fermentations. Data for optical density measurements are not included.

Additional file 2: Summary of fermentation data for yeast deletants compared to parent BY4743. CDGJM_200 $100 \mathrm{~mL}$ : Yeast deletants were compared with parent BY4743 in triplicated $100 \mathrm{ml}$ fermentations using CDGJM_200. The degree of protraction was determined as the fermentation duration ratio of the deletant compared to BY4743. 72 genes were identified as effecting fermentation. Durations of $120 \%$ and above were considered significant in exhibiting protracted fermentation An additional 29 genes were examined, 21 of which were shown to result in protracted fermentation in CDGJM_200. CDGJM 20 micro: Yeast deletants were compared with parent BY4743 in micro-scale fermentations using CDGJM_20. 101 clones were examined of which 72 were protracted in fermentation using CDGJM_200. Residual sugar and OD 600 was determined at $32 \mathrm{~h}$ and $56 \mathrm{~h}$.

Additional file 3: Comparison of the FEG dataset with the Fermentation Relevant Yeast Gene Databases LIT_FRYG and SGD_FRYG. Additional file 2 is a Microsoft Office Excel workbook relating to analysis of the genes identified in this study compared to previous research findings. Ninety three genes representing the FEG dataset were identified. Deletion of these genes resulted in protracted fermentation (20\% and greater when compared to parent, BY4743). See Additional file 1 for fermentation duration values. Two complementary databases of yeast genes related to fermentation, referred to as FRYG (acronym for Fermentation Relevant Yeast Genes) were generated. The first (LIT_FRYG) was compiled from relevant literature, examining single stress conditions relevant to fermentation. The second (SGD_FRYG), a compilation of phenotype terms as accessed on the SGD, whereby only null mutants (deletants) with a specific phenotype response, i.e. decreased resistance were selected. The 93 FEG were compared to the two FRYG datasets. Genes unique to this fermentation study (absent in the LIT_FRYG and SGD_FRYG) and two specific subsets of genes within the 93 FEG dataset ("Stuck mutants" and "vacuolar $\left(\mathrm{H}^{+}\right)$ATPase") are shown.

Additional file 4: Classification and numerical enrichment of the FEG annotated to biological process, function, and cellular component. Genes were classified using the computational tools Slim Mapper (SGD database; (http://www.yeastgenome.org/) and GOToolBox into categories based on GO terms for biological process, function and cellular component. Descriptions of the 93 FEG are taken from SGD database. Enrichment of genes annotated to particular GO terms includes corresponding $p$ values. $\mathrm{GO}$ terms were organised into $\mathrm{GO}$ biomodules using the web based visualisation tool GO-Module whereby K nodes refer to the key GO terms and T nodes refer to hierarchical descendents of K, regardless of statistical value ( $p$ value). F nodes represent the false positive prioritised GO terms in the input data. F nodes determined for particular GO terms were not precluded because of the nature of the GO term. Genes annotated to GO terms not defined through GO module and not significantly enriched were classified into groups using SGD Slim Mapper.

\section{Competing interests}

The authors declare no competing financial interests.

\section{Authors' contributions}

MEW drafted the manuscript, and JG and VJ were involved in editing and critical revision of manuscript for intellectual content. MEW was involved in the planning of the study. TL and FS designed and conducted the micro-fermentation studies together with MEW, NK and JG. Data analysis was conducted by MEW and JG. MEW, TDN and JS conducted lab scale fermentations. All authors read and approved the final manuscript.

\section{Acknowledgements}

This project is supported by Australia's grape growers and winemakers through their investment body the Grape and Wine Research Development Corporation, which matching funds from the Australian Government (GWDRC Projects UA 05/01 and UA05/06). PhD support for T.D.N. is from the Vietnamese Government and GWDRC.

Received: 28 October 2013 Accepted: 27 June 2014

Published: 3 July 2014

\section{References}

1. Pretorius IS: Tailoring wine yeast for the new millenium:novel approaches for the ancient art of wine making. Yeast 2000, 16:675-679.

2. Borneman AR, Desany BA, Riches D, Affourtit JP, Forgan AH, Pretorius IS, Egholm M, Chambers PJ: Whole-genome comparison reveals novel genetic elements that characterize the genome of industrial strains of Saccharomyces cerevisiae. PLoS Genetics 2011, 7:1-10.

3. Ando A, Tanaka F, Murata Y, Takagi H, Shima J: Identification and classification of genes required for tolerance to high-sucrose stress revealed by genome-wide screening of Saccharomyces cerevisiae. FEMS Yeast Res 2006, 6:249-267.

4. Teixeira MC, Raposo LR, Palma M, Sá-Correia I: Identification of genes required for maximal tolerance to high-glucose concentrations, as those present in industrial alcoholic fermentation media, through a chemogenomics approach. OMICS 2010, 14(2):201-210.

5. Reiner S, Micolod D, Zellnig G, Schneiter R: A genome-wide screen reveals a role of mitochondria in anaerobic uptake of sterols in yeast. $\mathrm{Mol}$ Biol cell 2006, 17:90-103. 
6. Tucker $\mathrm{CL}$, Fields S: Quantitative genome-wide analysis of yeast deletion strain sensitivities to oxidative and chemical stress. Comp Funct Genom 2004, 5:216-224

7. Abe $\mathrm{F}$, Minegishi $\mathrm{H}$ : Global screening of genes essential for growth in high-pressure and cold environments: Searching for basic adaptive strategies using a yeast deletion library. Genetics 2008, 178:851-872

8. Fujita K, Matsuyama A, Kobayashi Y, Iwahashi H: The genome-wide screening of yeast deletion mutants to identify the genes required for tolerance to ethanol and other alcohols. FEMS Yeast Res 2006, 6:744-750.

9. Teixeira MC, Raposo LR, Mira NP, Lourenço AB, Sá-Correia I: Genome-wide identification of Saccharomyces cerevisiae genes required for maximal tolerance to ethanol. Appl Env Micro 2009, 75(18):5761-5772.

10. van Voorst F, Houghton-Larsen J, Jønson L, Kielland-Brandt MC, Brandt A: Genome-wide identification of genes required for growth of Saccharomyces cerevisiae under ethanol stress. Yeast 2006, 23(5):351-359.

11. Mira NP, Palma M, Guerreiro JF, Sá-Correia I: Genome-wide identification of Saccharomyces cerevisiae genes required for tolerance to acetic acid. Microbial Cell Factories 2010, 9(79):13.

12. Winzeler EA, Shoemaker DD, Astromoff A, Liang H, Anderson $\mathrm{K}$, Andre B, Bangham R, Benito R, Boeke JD, Bussey H, Chu AM, Connelly C, Davis K, Dietrich F, Dow SW, El Bakkoury M, Foury F, Friend SH, Gentalen E, Giaever G, Hegemann JH, Jones T, Laub M, Liao H, Liebundguth N, Lockhart DJ, Lucau-Danila A, Lussier M, M'Rabet N, Menard P, et al: Functional characterization of the $S$. cerevisiae genome by gene deletion and parallel analysis. Science 1999, 285(5429):901-906.

13. Harsch MJ, Lee SA, Goddard MR, Gardner RC: Optimized fermentation of grape juice by laboratory strains of Saccharomyces cerevisiae. FEMS Yeast Res 2009, 10(1):72-82.

14. Beltran G, Esteve-Zarzoso B, Rozès N, Mas A, Guillamón J: Influence of the timing of nitrogen additions during synthetic grape must fermentation on fermentation kinetics and nitrogen consumption. J Agric Food Chem 2005, 53(4):996-1002.

15. Jiranek $V$, Langridge $P$, Henschke PA: Amino acid and ammonium utilization by Saccharomyces cerevisiae wine yeasts from a chemically defined medium. Am J Enol Vitic 1995, 46:75-83.

16. Alexandre $\mathrm{H}$, Charpentier A: Biochemical aspects of stuck and sluggish fermentation in grape must. $J$ Ind Microbiol Biot 1998, 20:20-27.

17. Henscke $P$, Jiranek V: Yeasts: Metabolism of nitrogen compounds. In Wine Microbiology and Biotechnology. Edited by Fleet GH. Chur: Harwood Academic Publishers; 1993:77-163.

18. Boulton RB, Singleton VL, Bisson LF, Kunkee RE: Principles and practices of winemaking. New York: Chapman \& Hall; 1996

19. Pizarro F, Vargas FA, Agosin E: A systems biology perspective of wine fermentations. Yeast 2007, 24:977-991.

20. Mülleder M, Capuano F, Pir P, Christen S, Sauer U, Oliver SG, Ralser MA: A prototrophic deletion mutant collection for yeast metabolomics and systems biology. Nat Biotechnol 2012, 30:1176-1178.

21. Tran T, Forgan A, Bartowsky E, Borneman AR: Construction of a wine yeast genome deletion library. In: Proceedings of the 12th International Conference on Culture Collections: 26 Sept - 01: Florianiópolis, Brazil. Brazilian Society of Microbiology Oct 2010, 2010:20.

22. Gardner J, McBryde C, Vystavelova A, de Barros Lopes M, Jiranek V: Identification of genes affecting glucose catabolism in nitrogen limited fermentation. FEMS Yeast Res 2005, 5:791-800.

23. Madlanga NH: Analysis of Saccharomyces cerevisiae deletion mutants displaying a modified carbon flux under wine fermentation conditions. Masters: University of Stellenbosch; 2009

24. Auesukaree C, Damnernsawad A, Kruatrachue M, Pokethitiyook P, Boonchird C, Kaneko Y: Genome-wide identification of genes involved in tolerance to various environmental stresses in Saccharomyces cerevisiae. J Appl Genet 2009, 50:301-310.

25. Mollapour M, Fong D, Balakrishnan K, Harris N, Thompson S, Schüller C, Kuchler K, Piper PW: Screening the yeast deletant mutant collection for hypersensitivity and hyper-resistance to sorbate, a weak organic acid food preservative. Yeast 2004, 21:927-946.

26. Snoek ISI, Steensma HY: Why does Kluyveromyces lactis not grow under anaerobic conditions? Comparison of essential anaerobic genes of Saccharomyces cerevisiae with the Kluyveromyces lactis genome. FEMS Yeast Res 2006, 6:393-403

27. Marks VD, Ho Sui SJ, Erasmus D, Van Der Merwe GK, Brumm J, Wasserman WW, Bryan J, van Vuuren HJ: Dynamics of the yeast transcriptome during wine fermentation reveals a novel fermentation stress response. FEMS Yeast Res 2008, 8(1):35-52.

28. Zakrzewska A, van Eikenhorst G, Burggraaff JEC, Vis DJ, Hoefsloot H, Delner D, Oliver SG, Brul S, Smits GJ: Genome-wide analysis of yeast stress survival and tolerance acquisition to analyze the central trade-off between growth rate and cellular robustness. Mol Biol Cell 2011 22(22):4435-4446.

29. Shima J, Ando A, Takagi H: Possible roles of vacuolar H+-ATPase and mitochondrial function in tolerance to air-drying stress revealed by genome-wide screening of Saccharomyces cerevisiae deletion strains. Yeast 2008, 25:179-190.

30. Martin D, Brun C, Remy E, Mouren P, Thieffry D, Jacq B: GoToolBox: functional investigation of gene datasets based on Gene Ontology. Genome Biol 2004, 5:R101.

31. Yang X, Li J, Lee Y, Lussier YA: GO-Module: functional synthesis and improved interpretation of Gene Ontology patterns. Bioinformatics 2011, 27:1444-1446.

32. Armstrong J: Yeast vacuoles: more than a model lysosome. Trends Cell Biol 2010, 20(10):580-585.

33. Stefan CJ, Emr SD: Vacuoles. In Encyclopedia of Biological Chemistry. Edited by William JL, Lane MD. New York: Elsevier; 2004:331-336.

34. Majara M, O'Connor-Cox ESC, Axcell BC: Trehalose - an osmoprotectant and stress indicator compound in high and very high gravity brewing. J Am Soc Brew Chem 1996, 54:149-154.

35. Mahmud SA, Hirasawa T, Shimizu H: Differential importance of trehalose accumulation in Saccharomyces cerevisiae in response to various environmental stresses. J Biosci Bioeng 2010, 109(3):262-266.

36. Trevisol ET, Panek AD, Mannarino SC, Eleutherio EC: The effect of trehalose on the fermentation performance of aged cells of Saccharomyces cerevisiae. Appl Microbiol Biotechnol 2011, 90(2):697-704.

37. An MZ, Tang YQ, Mitsumasu K, Liu ZS, Shigeru M, Kenji K: Enhanced thermotolerance for ethanol fermentation of Saccharomyces cerevisiae strain by overexpression of the gene coding for trehalose-6-phosphate synthase. Biotechnol Lett 2011, 33(7):1367-1374.

38. Hughes AL, Gottschling DE: An early age increase in vacuolar pH limits mitochondrial function and lifespan in yeast. Nature 2012 492(7428):261-265.

39. Goddard MR: Quantifing the complexities of Saccharomyces cerevisiae's ecosystem engineering via fermentation. Ecology 2008, 89(8):2077-2082.

40. Morano KA, Grant CM, Moye-Rowley WS: The response to heat shock and oxidative stress in Saccharomyces cerevisiae. Genetics 2012, 190(4):1157-1195

41. Saito H, Posas F: Response to hyperosmotic stress. Genetics 2012, 192(2):289-318.

42. Ariño J, Ramos J, Sychrová H: Alkali metal cation transport and homeostasis in yeasts. Micro Mol Biol Rev 2010, 74(1):95-120.

43. Rouault TA, Tong W-H: Iron-sulphur cluster biogenesis and mitochondrial iron homeostasis. Nat Rev Mol Cell Biol 2005, 6:345-351.

44. Voisine C, Schilke B, Ohlson M, Beinert H, Marszalek J, Craig EA: Role of the mitochondrial Hsp70s, Ssc1 and Ssq1, in the maturation of Yfh1. Mol Cell Biol 2000, 20(10):3677-3684.

45. McBryde C, Gardner JM, de Barros Lopes M, Jiranek V: Generation of novel wine yeast strains by adaptive evolution. Am J Enol Vit 2006, 57:423-430.

46. Schmidt SA, Dillon S, Kolouchova R, Henschke PA, Chambers PJ: Impacts of variations in elemental nutrient concentration of chardonnay musts on Saccharomyces cerevisiae fermentation kinetics and wine composition. Appl Micro Biotech 2011, 91(2):365-375.

47. Brett CLKL, Hua Z, Green R, Chyou A, Zhang Y, Graham TR, Donowitz M, Rao $\mathrm{R}$ : Genome-wide analysis reveals the vacuolar pH-stat of Saccharomyces cerevisiae. PLoS One 2011, 6(3):e17619.

48. Cyert MS, Philpott CC: Regulation of cation balance in Saccharomyces cerevisiae. Genetics 2013, 193(3):677-713.

49. Forgac M: Vacuolar ATPases: rotary proton pumps in physiology and pathophysiology. Nat Rev Mol Cell Biol 2007, 8(11):917-929.

50. Kane PM: The where, when and how of organelle acidification by the yeast vacuolar $\mathrm{H}^{+}$ATPase. Micro Mol Biol Rev 2006, 70:177-191.

51. Kane PM, Smardon AM: Assembly and regulation of the yeast vacuolar $\mathrm{H}^{+}$ ATPase. J Bioenerg Biomembr 2003, 35:313-321.

52. Makrantoni $V$, Dennison P, Stark MJR, Coote PJ: A novel role for the yeast protein kinase Dbf2p in vacuolar $\mathrm{H}^{+}$-ATPase function and sorbic acid stress tolerance. Microbio/ 2007, 153(12):4016-4026. 
53. Cagnac O, Aranda-Sicilia MN, Leterrier M, Rodriguez-Rosales MP, Venema K Vacuolar cation $/ \mathrm{H}^{+}$antiporters of Saccharomyces cerevisiae. J Biol Chem 2010, 285(44):33914-33922

54. Orij R, Brul S, Smits GJ: Intracellular $\mathrm{pH}$ is a tightly controlled signal in yeast. Biochim Biophys Acta 2011, 1810(10):933-944.

55. Martínez-Muñoz GA, Kane P: Vacuolar and plasma membrane proton pumps collaborate to achieve cytosolic $\mathrm{pH}$ homeostasis in yeast. J Biol Chem 2008, 283(29):20309-20319.

56. Delneri D, Hoyle DC, Kargkas KG, Cross EJM, Rash B, Zeef L, Leong H-S, Davey HM, Hayes A, Kell DB, Griffith GW, Oliver SG: Identification and characterization of high-flux-control genes of yeast through competition analyses in continuous cultures. Nature Genetics 2008, 40(1):113-117.

57. Souza MAA, Trópia MJ, Brandão RL: New aspects of the glucose activation of the H+-ATPase in the yeast Saccharomyces cerevisiae. Microbiology 2001, 147(10):2849-2855.

58. Gancedo JM: The early steps of glucose signalling in yeast. FEMS Microbiol Rev 2008, 32(4):673-704

59. Tisi R, Belotti F, Wera S, Winderickx J, Thevelein JM, Martegani E: Evidence for inositol triphosphate as a second messenger for glucose-induced calcium signalling in budding yeast. Curr Genet 2004, 45(2):83-89.

60. Tisi R, Baldassa S, Belotti F, Martegani E: Phospholipase $C$ is required for glucose-induced calcium influx in budding yeast. FEBS Letters 2002 , 520(1-3):133-138.

61. Pereira MBP, Tisi R, Fietto LG, Cardoso AS, França MM, Carvalho FM, Trópia MJM, Martegani E, Castro IM, Brandão RL: Carbonyl cyanide $\mathrm{m}$-chlorophenylhydrazone induced calcium signaling and activation of plasma membrane $\mathrm{H}+$-ATPase in the yeast Saccharomyces cerevisiae. FEMS Yeast Res 2008, 8(4):622-630.

62. Bouillet LEM, Cardoso AS, Perovano E, Pereira RR, Ribeiro EMC, Trópia MJM Fietto LG, Tisi R, Martegani E, Castro IM, Brandão RL: The involvement of calcium carriers and of the vacuole in the glucose-induced calcium signaling and activation of the plasma membrane $\mathrm{H}+$-ATPase in Saccharomyces cerevisiae cells. Cell Calcium 2012, 51(1):72-81.

63. Groppi S, Belotti F, Brandão RL, Martegani E, Tisi R: Glucose-induced calcium influx in budding yeast involves a novel calcium transport system and can activate calcineurin. Cell Calcium 2011, 49(6):376-386.

64. Wera S, Bergsma JCT, Thevelein JM: Phosphoinositides in yeast: genetically tractable signalling. FEMS Yeast Res 2001, 1(1):9-13.

65. Rolland F, Winderickx J, Thevelein JM: Glucose-sensing and -signalling mechanisms in yeast. FEMS Yeast Res 2002, 2:183-201.

66. Rubio-Texeira M, Van Zeebroeck G, Voordeckers K, Thevelein JM: Saccharomyces cerevisiae plasma membrane nutrient sensors and their role in PKA signalling. FEMS Yeast Res 2010, 10:134-149.

67. Palecek SP, Parikh AS, Kron SJ: Sensing, signalling and integrating physical processes during Saccharomyces cerevisiae invasive and filamentous growth. Microbiology 2002, 148(4):893-907.

68. Goossens A, de la Fuente N, Forment J, Serrano R, Portillo F: Regulation of Yeast $\mathrm{H}^{+}$-ATPase by Protein Kinases Belonging to a Family Dedicated to Activation of Plasma Membrane Transporters. Mol Cell Biol 2000, 20(20):7654-7661.

69. Nass $\mathrm{R}$, Rao R: The yeast endosomal $\mathrm{Na}^{+} / \mathrm{H}^{+}$exchanger, Nhx1, confers osmotolerance following acute hypertonic shock. Microbiology 1999, 145:3221-3228

70. Czyz O, Bitew T, Cuesta-Marbán A, McMaster CR, Mollinedo F, Zaremberg V: Alteration of plasma membrane organization by an anticancer lysophosphatidylcholine analogue induces intracellular acidification and internalization of plasma membrane transportersin yeast. J Biol Chem 2013, 288:8419-8432

71. Graham LA, Flannery AR, Stevens $T$ : Structure and assembly of the yeast V-ATPase. J Bioenerg Biomembr 2003, 35:301-312.

72. Zhang JW, Parra KJ, Liu J, Kane PM: Characterization of a temperaturesensitive yeast vacuolar ATPase mutant with defects in actin distribution and bud morphology. J Biol Chem 1998, 273:18470-18480.

73. Wada $Y$, Nakamura N, Ohsumi $Y$, Hirata A: Vam3p, a new member of syntaxin related protein, is required for vacuolar assembly in the yeast Saccharomyces cerevisiae. J Cell Science 1997, 110:1299-1306.

74. Plant PJ, Manolson MF, Grinstein S, Demaurex N: Alternative mechanisms of vacuolar acidification in $\left.\mathrm{H}^{+}\right)$-ATPase-deficient yeast. J Biol Chem 1999 274(52):37270-37279.
75. Aabo T, Glückstad J, Siegumfeldt H, Arneborg N: Intracellular pH distribution as a cell health indicator in Saccharomyces cerevisiae. Interface 2011, 8(64):1635-1643

76. Li SC, Diakov TT, Rizzo JM, Kane PM: Vacuolar $\mathrm{H}^{+}$-ATPase works in parallel with the HOG Pathway to adapt Saccharomyces cerevisiae cells to osmotic stress. Eukaryotic Cell 2012, 11(3):282-291.

77. Villa-García MJ, Choi MS, Hinz FI, Gaspar ML, Jesch S, Henry SA: Genomewide screen for inositol auxotrophy in Saccharomyces cerevisiae implicates lipid metabolism in stress response signalling. Mol Gen Genomics 2011, 285:125-149.

78. Dubouloz F, Deloche O, Wanke V, Cameroni E, De Virgilio C: The TOR and EGO protein complexes orchestrate microautophagy in yeast. Mol Cell 2005, 19:15-26.

79. Broach JR: Nutritional control of growth and development in yeast. Genetics 2012, 192(1):73-105.

80. Gao M, Kaiser CA: A conserved GTPase-containing complex is required for intracellular sorting of the general amino-acid permease in yeast. Nat Cell Biol 2006, 8:657-667.

81. Cebollero E, Gonzalez R: Induction of autophagy by second-fermentation yeasts during elaboration of sparkling wines. Appl Env Micro 2006, 72(6):4121-4127.

82. Piggott N, Cook MA, Tyers M, Measday V: Genome-wide fitness profiles reveal a requirement for autophagy during yeast fermentation. G3: Genes Genomes Genetics 2011, 1(5):353-367.

83. Liccioli T, Tran T, Cozzolino D, Jiranek V, Chambers P, Schmidt S: Microvinification - how small can we go? Appl Micro Biotech 2011, 89(5):1621-1628.

84. Walker ME, Gardner JM, Vystavelova A, McBryde C, de Barros Lopes M, Jiranek $\mathrm{V}$ : Application of the reuseable, KanMX selectable marker to industrial yeast: Construction and evaluation of heterothallic wine strains of Saccharomyces cerevisiae, possessing minimal foreign DNA sequences. FEMS Yeast Res 2003, 4:339-347.

doi:10.1186/1471-2164-15-552

Cite this article as: Walker et al:: Genome-wide identification of the Fermentome; genes required for successful and timely completion of wine-like fermentation by Saccharomyces cerevisiae. BMC Genomics 2014 15:552.

\section{Submit your next manuscript to BioMed Central and take full advantage of:}

- Convenient online submission

- Thorough peer review

- No space constraints or color figure charges

- Immediate publication on acceptance

- Inclusion in PubMed, CAS, Scopus and Google Scholar

- Research which is freely available for redistribution 